\title{
Juventude e Políticas Ambientais: A Percepção e os Discursos de Jovens Brasileiros
}

\author{
Antonio Teixeira de Barros*
}

\section{RESUMO}

Este artigo analisa as percepções e os discursos de jovens brasileiros sobre as políticas ambientais na atualidade, com base em questionário com perguntas abertas e fechadas. Enfatiza-se as respostas abertas, as quais apresentam as justificações dos respondentes para as questões postas. O suporte teórico utiliza contribuições da sociologia ambiental e da sociologia da juventude. As principais conclusões indicam que a percepção dos respondentes é predominantemente pessimista, acreditando que o Brasil está regredindo em suas políticas ambientais. Quanto às autoridades eleitas que atuam ou já atuaram na defesa do meio ambiente, os jovens reconhecem em especial os vereadores, prefeitos e deputados estaduais, o que demonstra a primazia das políticas locais na percepção da juventude. Mais do que o ato de proferir discursos, os jovens atribuem importância à participação dos agentes públicos no debate ambiental qualificado com vistas à proposição de mudanças ou de aperfeiçoamentos das políticas ambientais.

Palavras-chaves: Juventude; Meio ambiente; Políticas ambientais.

* Doutor em Sociologia pela Universidade de Brasília (1999). Docente e pesquisador do Programa de Mestrado em Ciência Política do Centro de Formação da Câmara dos Deputados. 


\begin{abstract}
YOUTH AND ENVIRONMENTAL POLICIES: THE PERCEPTION AND THE DISCOURSES OF BRAZILIANS YOUNG
\end{abstract}

This article analyzes the perceptions and discourses of Brazilian young people about environmental policies today, based on a questionnaire with open and closed questions. The emphasis is on the open answers, which present the justifications of the respondents for the questions posed. The theoretical support uses contributions from environmental sociology and the sociology of youth.The main conclusions indicate that the respondents' perception is predominantly pessimistic, believing that Brazil is regressing in its environmental policies. As for the elected authorities that act or have already been active in the defense of the environment, young people especially recognize councilors, mayors and state deputies, which demonstrates the primacy of local politics in the perception of youth.More than giving speeches, young people attach importance to the participation of public agents in the qualified environmental debate with a view to proposing changes or improvements in environmental policies. Keywords: Youth; Environment; Environmental policies.

\title{
Introdução
}

Para Acselrad (2001), o desenvolvimento das políticas ambientais no Brasil está diretamente relacionado à consolidação do regime democrático e à capacidade do Estado de atender a demandas sociais sobre qualidade de vida e sustentabilidade ecológica. A sustentabilidade é definida como a capacidade de uma comunidade ou sociedade satisfazer suas próprias necessidades sem reduzir ou comprometer as oportunidades das gerações futuras (BROWN, 1988; BURNS, 2016). Como se pode observar, a questão geracional já está implícita no próprio conceito. Além disso, a cultura da sustentabilidade passou a ser associada diretamente à juventude (AUTIO; HEINONEN, 2004; BARROS, 2015a; PITELIS, 2013).

Segundo projeções oficiais, quase 33\% dos 210 milhões de brasileiros são jovens e 85\% deles vivem em centros urbanos com reconhecidos problemas ambientais. Esses cidadãosvivenciam variados modos de debate sobre a agenda verde, a qual provocou discussões que "permeiam diversas áreas da nossa vida, influenciando as regras que precisamos seguir ou mesmo buscando regular o modo de vida a ser vivido”(SILVA, 2016, p.206).

Do ponto de vista das políticas ambientais, o Estado exerce um papel central. Trata-se de uma concepção próxima à ideia de Giddens (2009, p. 
96) de Estado assegurador, ou seja, significa que “o Estado é responsável por monitorar os objetivos políticos e por procurar certificar-se de que eles se concretizem de forma visível e aceitável”. Trata-se de uma visão similar desenvolvida por Sachs (2007) em seu conceito de ecossocioeconomia, segundo o qualo Estado também exerce protagonismo na definição de políticas de desenvolvimento sustentável em áreas estratégicas, como inovação tecnológica, industrial e energética (BARROS, 2015a; 2015b; 2017a; 2017b; 2018a; 2018b).

Com base nesse cenário mais amplo, o artigo tem como objetivo analisar as percepções e os discursos da juventude brasileira sobre as políticas ambientais na atualidade, com foco nos atores institucionais dessas políticas, especialmente o Estado, os órgãos ambientais e os partidos políticos. Tal abordagem se justifica em razão dos argumentos apresentados acima acerca do papel do Estado e dos atores políticos na formulação e revisão das políticas ambientais, incluindo as leis.

O referencial teórico reúne contribuições da Sociologia Ambiental e da Sociologia da Juventude, a partir da constatação de que no Brasil, "a investigação em torno da relação entre juventude e meio ambiente tem se apresentado como campo de estudo ainda bastante incipiente tanto do ponto de vista da Sociologia Ambiental quanto da Sociologia da Juventude” (SILVA, 2016, p.220). Para o autor, a atenção dada às percepções juvenis sobre as questões socioambientais, salvo raras exceções, "aparece como subproduto de estudos que procuram traçar um perfil da juventude brasileira e, portanto, secundarizada em termos de fenômeno e interesse sociológico” (p.220). Esse vazio de investigações, no seu entender, com o qual concordamos, "tende a corroborar a necessidade de um investimento mais amplo em pesquisas, dentro da especificidade da temática, para que seja possível identificar um processo mais amplo, ou não, de ambientalização dos discursos e de práticas juvenis” (SILVA, 2016, p.220)

A metodologia consistiu na aplicação de survey aplicado com uma amostragem nacionala 1.225 jovens de 15 a 29, com questões fechadas e abertas, durante o mês de outubro de 2018. O questionário foi aplicado no formato do Google Forms, para facilitar a coleta de dados. Para a construção do questionário, utilizamos a técnica do painel delphi (LINSTONE; TUROFF, 1975; MARQUES; FREITAS, 2018). Trata-se de uma técnica que, entre outras finalidades, consiste na consulta à opinião de especialistas sobre as questões 
mais adequadas para a elaboração de um questionário de pesquisa, a fim de conferir maior validade ao instrumento de coleta de dados de um survey. Foram oito os especialistas consultados, entre sociólogos, cientistas políticos e estudiosos sobre juventude.

A divulgação da pesquisa foi realizada durante dois meses (setembro e outubro de 2016) por meio das redes sociais digitais como Facebook, Twitter, Google+ e WhatApp. Outra estratégia foi a divulgação entre websites e perfis de redes sociais de escolas, universidades e coletivos de jovens, abrangendo as cinco regiões geográficas do Brasil.O critério etário (15 a 29 anos) tem como base o Estatuto da Juventude (Lei Federal n. 12.852/2013), que estabelece as diretrizes gerais para as políticas de juventude no Brasil. Segundo essa lei,são consideradas jovens as pessoas com idade entre 15 e 29 anos de idade.

As justificativas apresentadas nos itens abertos para comentários ajudam a compreender as percepções expressas nas respostas das questões fechadas. Isso porque os comentários livresapresentam visões muito diversificadas. Optamos, portanto, por agrupar os principais argumentos-chave, seguindo a técnica qualitativa da análise temática, entendida como agrupamento semântico das respostas, conforme o tema abordado pelos informantes(BARDIN, 2005).

\section{Meio Ambiente e Juventude}

McNeill (2001) considera o século XX como o século do ambientalismo. Para o autor, a história da política internacional é mais frequentemente contada através das guerras mundiais, da ascensão e queda de regimes políticos ou das crises econômicas. No caso do século XX, contudo, para o autor, apesar de eventos críticos como as guerras mundiais e a derrocada do comunismo, a história ambiental seria o principal legado do século XX. O debate sobre a crise envolvendo os global commons e osriscos ambientais também contribui para que o tema fosse posto em relevo na agenda pública global (HARDIN, 1998; VOGLER, 2012; ROHRSCHNEIDER; MILES, 2015; CHAFFIN et al., 2016; PEPERMANS, 2016; BIERMANN, 2017; RYAN, 2017).

Antes de serem incorporadas às arenas políticas, as pautas ambientais passaram por uma longa e complexa trajetória de variados tipos de ambientalismos, dos mais radicais (ecossocialismo), aos mais moderados que resultaram no chamado capitalismo verde ou ambientalismo liberal (SMITH, 
2016; BRAND, 2015; CHAMBOREDON, 2015; WANNER, 2015).Destaca-se ainda o socioambientalismo, ao propor a superação das dicotomias existentes entre as questões sociais e ambientais, além de defender maior participação dos movimentos sociais na elaboração de políticas públicas ambientais (SANTILLI, 2005). ${ }^{1}$ Diversos discursos se formaram antes das convergências para desenvolvimento e sustentabilidade ambiental (BARROS, 2015a; PERSSON, 2018; LIM, SØGAARD; WYBORN, 2018). Cada vertente possui a sua própria identidade, visto que cada uma delas constitui um campo particular de disputas, com sua natureza própria, seus interesses, suas lógicas e estratégias de ação (IRWIN, 2013). O reconhecimento de tal pluralidade é indispensável para evitar o equívoco do pressuposto de um pensamento ecológico único e monolítico, mesmo quando se trata do conceito de capitalismo verde ou ambientalismo liberal (YEARLEY, 2014; CHAKRABARTY, 2017; BARROS, 2018).

Conforme Inglehart (1977), o ambientalismo insere-se em uma nova ordem de necessidades, que transcende a esfera material e coloca na cena pública o debate sobre temas cuja força principal está no conteúdo simbólico, imaterial e intangível, embora o caráter econômico não seja excluído. Nesse sentido, para o autor, o ambientalismo provocou uma revolução silenciosa na política contemporânea, em termos de mudança de valores, especialmente nas sociedades mais avançadas, nas quais a agenda pós-materialista é mais intensa, especialmente nas metrópoles (IRAZÁBAL, 2017; IRWIN, 2013;HANNIGAN, 2014; DUNLAP; BRULLE, 2015). O debate sobre mudanças climáticas foi outro fator relevante nesse processo (LUKE, 2015; DUNLAP; MCCRIGHT; JERROD. 2016), combinado com outras questões associadas à sustentabilidade em suas várias dimensões (HANNIGAN, 2014; LEFF, 2015; JACOBBI; GIATTI, 2017; FRANCHINI, 2017; LEFF, 2017; IRAZÁBAL, 2017).

As gerações que atualmente estão na escola, na universidade ou ingressando no mercado de trabalho passaram por uma socialização em que o consumo passou a ser questionado e associado à crise ambiental (SCHARF; ROSA; OLIVEIRA, 2012). Assim, a socialização da juventude em contexto de crise ambiental e climática contribuiu para a construção de uma afinidade maior dos jovens em relação ao debate ecológico. A escola, enquanto espaço

1 Convém ressaltar que a literatura registra uma diversidade de nomenclaturas e classificações dos discursos ambientais. Dryzek (1997) ressalta quatro categorias: sobrevivencialismo, resolução de problemas, sustentabilidade e radicalismo verde. 
educativo formal e de socialização, também passou a exercer um papel significativo para a formação dessas das gerações, no que tange às discussões sobre meio ambiente (CRISTO, 2017).

Em razão disso, alguns autores (KRISCHKE, 2008; SILVA, 2016) têm chamado a atenção para o fato de que a agenda ambiental tem representado um campo importante para o estabelecimento de nova cultura política entre os jovens. Além de uma sensibilidade maior dos públicos juvenis às informações e mensagens relativas às temáticas ecológicas, existem predisposições próprias da idade que favorecem o engajamento em projetos e práticas relacionados à sustentabilidade. Alguns estudos ressaltam que é notório o papel central da juventude na transformação dos modelos socioambientais (CARVALHO, 2012; SILVA, 2016). Apesar disso, outros autores chamam a atenção para a necessidade de um olhar mais crítico sobre esse engajamento:

a associação mais imediata entre a juventude e o meio ambiente aponta para uma convergência incompleta, em que se percebe que os discursos de parte destes jovens estão bem distantes da prática efetiva de defesa, proteção e cuidados socioambientais. No entanto, isso não contradiz o fato de que a revalorização da natureza se tem se mostrado particularmente atrativa para o engajamento juvenil nas questões ambientais (SILVA, 2016, p.221)

Várias pesquisas sobre a relação entre juventude e política mostram que o afastamento dos jovens da política partidária não implica apatia ou rejeição à democracia (AUGUSTO, 2008; FLORENTINO, 2009; BARROS, 2018). Oliveira (2018, p.62) registra que os jovens passaram a preferir formas despartidarizadas de ação política. Como exemplo o autor cita a adesão preferencial de jovens a "grupos alternativos de arte, cultura, música, meio ambiente, movimentos de identidades, movimentos anarquistas, movimento étnico, dentre outros”. Para o autor,

a grande participação da juventude nesses grupos, se dá porque muitos desses espaços dialogam com as questões, necessidades e demandas juvenis. Além disso, são nesses espaços que muitos jovens se sentem inseridos, ganhando visibilidade, voz e participação, funcionando também como importantes espaços de afirmação (OLIVEIRA, 2018, p.62). 
Outra forma de participação política e de ação associativa que atrai os jovens são os coletivos (MAIA, 2013), caracterizados pela liderança horizontal, a cooperação e o uso das mídias sociais. Isso explica a predisposição de segmentos juvenis para a participação democrática em coletivos, políticas e projetos ambientais, inclusive no âmbito governamental. Nesse processo, o consumo consciente passou a fazer parte das pautas e da agenda política da juventude, impulsionando projetos de ação coletiva juvenil voltados para a sustentabilidade e o combate ao excessivo consumo de produtos descartáveis, como os plásticos que se acumulam atualmente nos oceanos e prejudicam a fauna e os ecossistemas marinhos (DE LA TORRE, 2017).

No âmbito governamental, um exemplo específico de participação democrática juvenil na área ambiental foi o Plano Nacional de Juventude e Meio Ambiente (PNJMA), finalizado em 2015. O referido plano é considerado uma política pública "construída a partir da demanda das organizações juvenis" (SOUSA, 2017, p.13). Na mesma perspectiva, Batista, Becker e Cassol (2015, p.172) ressaltam que o PNJMA tinha entre seus princípios orientadores a participação juvenil em todas as suas etapas. Os autores destacam ainda que a concepção do PNJMA levou em conta o papel estratégico da juventude como agente de transformação frente à crise ambiental, no sentido de (re) construção de novos estilos de vida, em consonância com as diretrizes para uma sociedade mais sustentável, pautada pela noção de justiça ambiental. Outro exemplo é a pesquisa de Fernandes (2010, p.11), que aponta a relevância da participação juvenil nas políticas de educação ambiental, reconhecendo esse campo como um espaço de protagonismo dos jovens.

Os exemplos citados se referem à participação de segmentos muito específicos, mediante a atuação de representantes de entidades juvenis. Faltam espaços mais amplos para a participação juvenil nas políticas ambientais, especialmente no plano local(DE LA TORRE, 2017). Além disso, é cabível questionar até que ponto a representação na participação desses representantes é de fato democrática. Nesse sentido, é oportuno mencionar o estudo de Lüchmann (2007), que chama a atenção para a necessidade de se considerar o caráter democrático da representação no interior das práticas de participação.

Estudar as relações dos jovens com a sustentabilidade requer uma breve abordagem sobre o jovem como sujeito político. Segundo Bourdieu (1983, p.112), a idade é um dado biológico socialmente manipulado e manipulável e 
que o fato de "falar dos jovens como se fossem uma unidade social, um grupo constituído, dotado de interesses comuns, e de relacionar estes interesses a uma idade definida biologicamente já constitui uma manipulação evidente”.

Convém mencionar aqui o conceito de geração, que é central na sociologia da juventude, desde os estudos pioneiros de Karl Mannheim (1968), entendido como além da faixa etária, ou seja, no sentido de compartilhamento de determinadas experiências de vida, de construção de referências socioculturais. Cabe ressaltar o argumento de Mannheim de que a simples coexistência no mundo, no sentido cronológico, não pode ser considerado fator decisivo para assegurar que um grupo faça parte da mesma geração (COFFEY; FARRUGIA, 2014; ATTIAS-DONFUT, 2015; WALLACE; CROSS, 2018).

O estudo sociológico das gerações tem uma longa tradição, que remete a pensadores como Auguste Comte, François Mentré, Ortega y Gasset, Julian Marías, Karl Manhein e Wilhelm Dilthey, entre outros. A questão inicial, de ordem cronológica e biológica, estava centrada no tempo, ou seja, quando uma geração termina e a outra começa.Para Corsten (1999), no estudo das gerações, é necessário considerar um horizonte interpretativo, de fundo cognitivo, como catalisador de uma coincidência de diferentes perspectivas de tempo, que são biográficos, históricos e tempos de geração. $\mathrm{O}$ vínculo geracional é ancorado na vivência e na reflexão coletiva acerca desses acontecimentos. Dessa forma, as gerações participam dos mesmos acontecimentos históricos e compartilham estilos e regimes de vida, por meio da socialização (FEIXA; LECCARDI, 2010; BARGEL; DARMON, 2016).

No caso da relação entre gerações e sustentabilidade, é necessário considerar a multiplicidade de fatores que condicionam as experiências sociais dos jovens com as questões e práticas ecológicas, como, por exemplo, “a classe social de sua família, se sua moradia é em área rural ou urbana, se pertence ou não a grupos étnicos marginalizados, seu gênero, opção religiosa, dentre tantos outros recortes possíveis” (FLORENTINO, 2009, p.217).

Em outras palavras, embora a juventude seja representada sociologicamente como "uma categoria relacional que posiciona os indivíduos como pertencentes a uma dada faixa etária” (GOHN, 2013, p.205), as pesquisas recentes mostram que existem várias juventudes. Cada vez mais, os jovens passam a ser caracterizados como um grupo social plural e emergente, o que requer olhares menos simplificadores. De modo geral, as culturas juvenis são mais fartamente associadas aos movimentos culturais, ao lazer, à contes- 
tação política e às transformações sociais dos costumes e dos modos de vida (ROBERTS; PARSELL, 1990). O envolvimento das juventudes com a sustentabilidade é mais frequentemente associado ao senso de responsabilidade que aumenta na fase de transição para a adultez (MÜLLER, 2009; BRUNET; PIZZI, 2013;LOZANO VICENTE, 2014; VAN DE VELDE, 2015).

Na sociologia da juventude, é consensual a ideia de que os jovens não são uma categoria unívoca, mas uma categoria construída culturalmente. Chamama atenção, ainda, as múltiplas configurações e perfis de juventudes e as pluralidades de culturas juvenis, condicionadas pela época, pela globalização cultural, pelos contextos e locais, além das especificidades e variações da conjuntura econômica, política, cultural e educacional (LAGREE, 1992; GAUTHIER, 2002; REVILLA CASTRO, 2001; GALLAND, 2017).

Trata-se de uma crítica às abordagens essencialistas, que desconsideram as especificidades e contextualidades que interferem na produção social dos comportamentos e das condições do juvenil (REGUILLO, 2003). Numa perspectiva histórica, Castro (2009), argumenta que a categoria geração é processada pela história, a cultura e o contexto. Em outras palavras, mais do que um marcador social, a idade tem mais relação com a época em que o indivíduo é socializado e suas questões.

\section{Análise dos Dados}

O perfil dos respondentes mostra equilíbrio entre homens e mulheres, com 50,69 \% do sexo masculino e 49,31\% do sexo feminino, como se vê no Quadro 1. Os três níveis de faixa etária estão bem representados, predominando os de 15 a 19 anos, com 40,41\%. Quanto à renda familiar, os segmentos mais expressivos encontram-se na escala de até cinco salários-mínimos (65,23\%). Em relação à escolaridade, predominam os que estão no Ensino Fundamental e no Ensino Médio $(90,44)$. Os residentes em capitais e regiões metropolitanas estão em maioria, com 72,16\%, respectivamente. No que se refere à região geográfica, prevalecem os residentes nas regiões Norte e Centro-Oeste $(63,51 \%)$, exatamente as que concentram as maiores quantidades de jovens do Brasil. 
Quadro 1 - Perfil dos respondentes

\begin{tabular}{|c|c|c|}
\hline SEXO & $\mathrm{N}$ & $\%$ \\
\hline Masculino & 621 & 50,69 \\
\hline Feminino & 604 & 49,31 \\
\hline Subtotal & 1225 & 100,00 \\
\hline \multicolumn{3}{|l|}{ FAIXA ETÁRIA } \\
\hline 15 a 19 anos & 495 & 40,41 \\
\hline 20 a 24 anos & 386 & 31,51 \\
\hline 25 a 29 anos & 344 & 28,08 \\
\hline Subtotal & 1225 & 100 \\
\hline \multicolumn{3}{|l|}{ RENDA FAMILIAR } \\
\hline Até 2 salários-mínimos & 402 & 32,82 \\
\hline 3 a 5 salários-mínimos & 397 & 32,41 \\
\hline 6 a 10 salários-mínimos & 205 & 16,73 \\
\hline 11 a 14 salários-mínimos & 123 & 10,04 \\
\hline Acima de 15 salários-mínimos & 98 & 8,00 \\
\hline Subtotal & 1225 & 100 \\
\hline \multicolumn{3}{|l|}{ ESCOLARIDADE } \\
\hline Ensino Fundamental Completo & 411 & 32,75 \\
\hline Ensino Médio Incompleto & 398 & 31,71 \\
\hline Ensino Médio Completo & 326 & 25,98 \\
\hline Curso Superior Incompleto & 43 & 3,43 \\
\hline Curso Superior Completo & 29 & 2,31 \\
\hline Pós-Graduação Incompleta & 27 & 2,15 \\
\hline Pós-Graduação Completa & 21 & 1,67 \\
\hline Subtotal & 1255 & 100 \\
\hline \multicolumn{3}{|l|}{ LOCAL DE RESIDÊNCIA } \\
\hline Capital & 523 & 42,69 \\
\hline Região Metropolitana & 361 & 29,47 \\
\hline Cidade do Interior & 249 & 20,33 \\
\hline Povoado & 92 & 7,51 \\
\hline Subtotal & 1225 & 100 \\
\hline \multicolumn{3}{|l|}{ REGIÃO GEOGRÁFICA } \\
\hline Norte & 391 & 31,92 \\
\hline Centro-Oeste & 387 & 31,59 \\
\hline Nordeste & 219 & 17,88 \\
\hline Sudeste & 126 & 10,29 \\
\hline Sul & 102 & 8,33 \\
\hline Subtotal & 1225 & 100 \\
\hline
\end{tabular}

Fonte: Dados dos autores, 2018. 
O questionário aplicado apresenta um conjunto de questões cujo foco são as políticas ambientais de responsabilidade de órgãos governamentais e atores políticos federais, estaduais e municipais. A principal justificativa para o enfoque representado pelo conjunto de perguntas aqui adotado deve-se à baixa quantidade de estudos que exploram tal perspectiva. Como já foi demonstrado anteriormente, o foco das pesquisas sobre juventude e meio ambiente tem explorado mais o engajamento em ações protagonizadas por coletivos, entidades do terceiro setor e voluntariado (FERNANDES, 2010; MAIA, 2013; DE LA TORRE, 2017).

A percepção dos respondentes sobre o ritmo das políticas ambientais brasileiras é bem diversificada, com perspectivas otimistas e pessimistas. Predominam, contudo, as visões dos que acham que o país está regredindo muito $(43,43 \%)$ e dos que avaliam que o progresso é lento $(20,73 \%)$. Aqueles que pensam que o Brasil já esteve melhor em relação às políticas ambientais somam $24,37 \%$, os que avaliam que está progredindo somam 10,66\%.

O pessimismo é justificado pelos respondentes, com base em exemplos recentes que são avaliados por eles como "retrocessos irreparáveis", como as modificações feitas pelo Congresso Nacional no Código Florestal em 2012. "As alterações feitas só favorecem o agronegócio e prejudicam os biomas brasileiros, com impactos ambientais muito negativos", como afirma um dos respondentes. Outros argumentos acionados se referem aos desastres ambientais, a exemplo do rompimento da barragem em Mariana, no Estado de Minas Gerais, em 2015. "Esses desastres não podem ser considerados acidentes e o Governo também é responsável, porque não pune de forma adequada os responsáveis e isso estimula a impunidade", argumenta outro informante.

Nesse sentido, os jovens que avaliam que as políticas ambientais estão progredindo explicam que isso se deve principalmente "às pressões internacionais, pois os casos de degradação da Amazônia chamam a atenção do mundo inteiro e isso força o Governo a adotar medidas legais para a proteção ambiental”, conforme explica um dos informantes. Outro argumento complementar é que o"Brasil está sempre em evidência na mídia internacional devido aos problemas ambientais, principalmente pelo desmatamento da Amazônia, o que obriga os governantes a tomarem alguma medida legal”. Nessa perspectiva, os jovens compreendem as políticas ambientais como reativas, ou seja, como resposta às pressões internacionais. É oportuno ressaltar que essa interpretação também aparece na literatura, conforme aponta 
Barros (2015), ao analisar como a agenda internacional influenciou a formulação de políticas públicas ambientais no Brasil, desde a década de 1970, após a Conferência de Estocolmo, até a atualidade.

Na opinião dos que acham que o Brasil está progredindo, mas lentamente, ainda existem muitos entraves que impedem um avanço mais expressivo das políticas ambientais no Brasil, “[...] como a própria burocracia estatal, os interesses econômicos envolvidos e falta de compromisso governamental com políticas efetivas de combate aos crimes ambientais”, conforme relata um dos informantes. Para os que pensam que o Brasil já esteve melhor em relação às políticas ambientais, a principal justificativa é que "os interesses do agronegócio estão cada vez mais fortes e evidentes, inclusive com a ampliação do número de parlamentares comprometidos com esse setor no Congresso Nacional”. Para outro informante, “o predomínio dos interesses econômicos dos ruralistas no parlamento impede o avanço de políticas ambientais e de leis mais adequadas para garantir a preservação”. Os que pensam que o Brasil está regredindo usam justificativas similares, mas de forma mais dramática, sob o argumento de que "o Congresso Nacional aprova anistia para os latifundiários e flexibiliza os critérios de fiscalização, a fim de evitar a punição dos grandes produtores da agricultura e da pecuária”.

Esse panorama sobre as percepções e os discursos dos jovens é relevante para demonstrar a heterogeneidade de visões, a qual certamente resulta da diferenciação de experiências desses sujeitos no que se refere às políticas ambientais. Além disso, é necessário ressaltar a heterogeneidade de juventudes e de culturas juvenis, noção que também deve ser considerada quando se trata da questão ambiental (KRISCHKE, 2008). No caso do Brasil, isso é ainda mais evidente, considerando as diferenciais regionais e as experiências desses jovens no âmbito ecológico quando se trata de metrópoles, cidades médias e pequenas.

Perguntados se conhecem alguma lei de caráter ambiental aprovada nos últimos cinco anos, a maioria respondeu que sim $(52,49 \%)$. Nesse caso, a lei mais citada foi o Novo Código Florestal, aprovado em 2012 (Lei Federal n. 12.727/12). Os que sabem que existem tais leis, mas não conseguem mencioná-las somam 37,22\% e apenas 10,29\% afirmam não conhecer as leis ambientais recentes. A menção quase unânime dos 52,49\% mencionados certamente se deve à ampla visibilidade midiática do tema em função das controvérsias políticas geradas, conforme registra Ab’Sáber (2010). Segundo o autor, enquanto o debate internacional colocava em foco a adoção de me- 
didas para reduzir as emissões de CO2, o projeto aprovado pelo Congresso Nacional teve como eixo a revisão das normas legais para flexibilizar a legislação brasileira, considerada pelos congressistas excessivamente rigorosa.

Além do Novo Código Florestal, também foi mencionada pelos informantes a lei que instituiu a Política Nacional de Resíduos Sólidos (Lei Federal n.12.305/2010). Os jovens que a mencionaram destacam que "essa lei, apesar de ser muito importante para a qualidade de vida e a saúde da população, na verdade, ainda é uma promessa, pois aqui onde eu moro ainda não está sendo cumprida e o lixo ainda causa problemas à população local”. Outro depoimento destaca a falta de fiscalização e de punição rigorosa para quem não cumpre a lei: "até o momento, não soube de nenhum tipo de punição para as Prefeituras que não fizeram seus planos de gerenciamento de resíduos sólidos, o que estimula a impunidade e o não cumprimento da lei”.

Também foram mencionadas, em menor escala, a lei que trata da gestão de florestas públicas para a produção sustentável (Lei federal 11.284/2006) e a lei que institui a Política Nacional sobre Mudança do Clima (Lei Federal n.12.187/2009). Ambas foram lembradas pelos jovens sob uma perspectiva crítica. Quanto à primeira, um dos relatos destaca que se trata "de uma lei muito importante, mas que praticamente foi esquecida e quase não se fala mais dela e dos benefícios que ela poderia gerar para a preservação das florestas, mesmo permitindo a exploração econômica”. A segunda foi mencionada por um dos respondentes como "uma lei para inglês ver, ou seja, foi anunciada somente para o Brasil ficar bem perante os demais países, sem nenhum efeito prático no plano interno”.

Apesar de terem sido mencionadas apenas quatro leis, é interessante destacar como os discursos dos jovens revelam conhecimento crítico sobre a finalidade e os efeitos da legislação ambiental brasileira. Cabe destacar ainda que se trata de leis com ampla visibilidade midiática e uma com fortes vínculos com a cultura da Amazônia. Tanto é que a lei sobre as florestas foi lembrada e criticada por jovens da Região Norte do País.

Quanto à agenda legislativa sobre meio ambiente, ou seja, os projetos de leis em discussão, o maior nível de conhecimento dos informantes diz respeito ao nível local, o que compreende os projetos em discussão nas Câmaras Municipais dosVereadores, com 95,76\% de respostas. No tópico do questionário aberto para comentários, os jovens justificam as razões que explicam essa preocupação maior com a agenda local.Os comentários se referem a 
projetos de leis sobre a destinação de resíduos sólidos, planos municipais de meio ambiente, política municipal de proteção de mananciais e arborização de praças e parques públicos.

Além de estarem atentos à agenda ecológica local, os jovens manifestam preocupações e críticas acerca da condução e do andamento dessa agenda, especialmente quando se trata dos acordos políticos locais que, na maioria das vezes, segundo a interpretação deles, “dificultam a aprovação de leis ambientais ou resultam em leis mais brandas e menos eficientes para a proteção do meio ambiente”, conforme revela um dos depoimentos. Outro informante ressalta que "parece que os políticos locais pensam mais em defender os interesses dos latifundiários, dos grandes produtores rurais e empresários do agronegócio do que na defesa ambiental propriamente dita”.

É importante registrar que mais de 90\% das menções a projetos de leis referiam-se ao âmbito das Câmaras Municipais dosVereadores e cerca de 10\% das Assembleias Legislativas estaduais. Não houve menção a projetos de leis em discussão na Câmara dos Deputados e nem no Senado Federal. Esse vínculo preferencial dos jovens com o ambiente local reforça estudos que mostram que a vivência democrática tem como base o âmbito local, no qual o cidadão tem suas experiências mais concretas (BAQUERO; CREMONESE, 2009).

Segundo essa ótica, o espaço urbano local passa a ser concebido como estruturador da cultura, de suas dinâmicas e conflitos, incluindo os jovens e sua relação com o meio ambiente. Trata-se de uma visão ancorada na representação da cidade como território político (ACSELRAD, 2011), entendido como espaço de uso coletivo, de habitação, de trânsitos e de tensões entre habitantes, lideranças políticas e outros atores locais. Por essas razões, quando se trata de estudos sobre as juventudes, as relações políticas tecidas no âmbito local constituem "campo privilegiado de análise porque nele as relações entre sociedade civil e Estado aparecem de forma mais clara” (SPOSITO, 2006, p.239).

Nesse sentido, o estudo de Barros (2018c) mostra que, apesar do desencanto da juventude com a política e a democracia representativa, há maior afinidade desse segmento com as políticas locais. A explicação existente na literatura é que os jovens tendem a se envolver mais com as questões relacionadas a seu contexto político imediato, marcado pela constituição de suas relações sociais, da construção de seus interesses e suas preferências, com as mediações das relações de reciprocidade e proximidade física e simbólica (AUGUSTO, 2005; AUGUSTO, 2008; TEIXEIRA COELHO, 1997). 
Estudos recentes mostram que o lugar (cidade, bairro, rua) constituiuma importante relação com a identidade dos jovens, um relevante marcador simbólico que representa a diferença em relação aos jovens que residem em outro local. O lugar também significa segurança, devido ao sentimento de pertencimento (MENEZES, 2015; JUNQUEIRA ET AL, 2015). A relação da juventude com o território vai além da dimensão material e política, pois implica sentimentos e afetos. A criação de laços sociais é que mobiliza esses atores para o cuidado em relação ao espaço onde (con)vivem (JUNQUEIRA ET AL, 2015). Essas razões reforçam as explicações sobre o maior interesse dos jovens inquiridos pelas políticas ambientais locais.

Conforme se lê no Quadro 2, os jovens consideram as ONGs ambientalistas as instituições mais atuantes na defesa do meio ambiente no Brasil, com $30,84 \%$. O Ibama aparece em segundo lugar, com 18,78\%. As demais instituições são pouco expressivas na percepção dos jovens, inclusive aquelas cuja atribuição principal é a defesa do meio ambiente, como a polícia ambiental (3,69\%).Evidencia-se, ainda, o baixo reconhecimento dos partidos ecológicos, com apenas 2,99\%, apesar de existirem três partidos de orientação ecológica no Brasil: o Partido Verde (PV), o Partido Ecológico Nacional $(\mathrm{PEN})^{2}$ e a Rede Sustentabilidade. Certamente, esse tipo de posicionamento dos jovens reflete a baixa confiança nos partidos políticos e nas instituições do Estado de modo geral, conforme mostram Barros e Martins (2016). No espaço do questionário destinado aos comentários, só houve registros de opiniões sobre a atuação das ONGs, os quais podem ser resumidos no seguinte relato: "Eu prefiro confiar nas ONGs, pois elas são mais transparentes e mostram que efetivamente estão empenhadas na defesa das causas ambientais”.

É oportuno frisar o silêncio dos jovens em relação aos órgãos institucionais quando se trata das políticas ambientais. Apesar das menções ao Ibama (19,14\%), não houve registro de comentários ou críticas à atuação de tal instituição. Destaca-se, outrossim, a baixa menção aos órgãos responsáveis pelas políticas ambientais no âmbito local, como as Prefeituras (7,02\%) e a falta de depoimentos sobre a atuação dessas instituições. Cabe ressaltar que o silêncio também funda e fundamenta o sentido (ORLANDI, 1997). Na visão da autora, o silêncio sobre algo chama a atenção para significar que se

2 O PEN mudou sua denominação para Patriota, em 2017, mas manteve em seu programa a proposta ecológica original, além de incorporar outros temas, como segurança pública e combate à criminalidade. 
estabelece pela ausência ou pela política do silêncio, ou seja, o apagamento instituído de certos sentidos em determinadas conjunturas. Nessestermos, cabe questionar o que significa o silêncio dos jovens sobre a atuação das instituições públicas e dos partidos políticos na área ambiental.

Tais percepções são constituídas certamente pela relação dos públicos jovens com as fontes de informação ambiental, especialmente sob a perspectiva da confiança desses públicos nos emissores. Quanto a isso, o estudo de Gonzalez-Gaudiano e Maldonado-Gonzalez (2014)revela que as principais fontes de informação ambiental para a juventude são a TV em primeiro lugar, seguida das mídias sociais, professores, familiares, amigos, jornalistas e ambientalistas. Entretanto, ao serem indagados sobre a confiança nas informações relativas a questões ambientais, em primeiro lugar, estão os cientistas, seguidos dos ambientalistas, educadores ambientais, organismos ligados às Nações Unidas, aos professores, meios de comunicação, amigos e familiares. As fontes menos confiáveis para esse público são: empresários, Prefeituras Municipais, Governos estaduais e órgãos do Governo Federal. Isso explica grande parte dos dados expostos no Quadro 2, especialmente no que se refere às percepções positivas acerca das ONGs ambientalistas e o crédito menor aos órgãos governamentais, como as Prefeituras, o Governo federal, Congresso Nacional, Câmaras Municipais e Governos Estaduais, entre outros.

Quadro 2 - Que instituições você considera mais atuantes na defesa do meio ambiente no Brasil?

\begin{tabular}{|c|c|c|}
\hline RESPOSTAS & $\mathrm{N}$ & $\%$ \\
\hline ONGs ambientalistas & 568 & 31,42 \\
\hline Ibama & 346 & 19,14 \\
\hline Prefeituras & 127 & 7,02 \\
\hline Governo Federal & 121 & 6,69 \\
\hline Congresso Nacional & 118 & 6,53 \\
\hline Câmaras Municipais dosVereadores & 113 & 6,25 \\
\hline Governo do Estado & 99 & 5,48 \\
\hline Poder Judiciário & 93 & 5,14 \\
\hline Assembleias Legislativas estaduais & 89 & 4,92 \\
\hline Polícia Ambiental & 68 & 3,76 \\
\hline Partidos políticos alinhados com temáticas ecológicas & 54 & 2,99 \\
\hline Outros & 12 & 0,66 \\
\hline Não sei avaliar & 0 & - \\
\hline TOTAL & 1808 & 100 \\
\hline
\end{tabular}

Fonte: Dados dos autores, 2018. 
Em relação às autoridades eleitas que atuam ou já aturam na defesa do meio ambiente, os jovens mostram maior conhecimento sobre as autoridades locais, especialmente os vereadores $(45,05 \%)$ e prefeitos $(23,19 \%)$, seguidos dos deputados estaduais (21,33\%), como se lê no Quadro 3. Novamente, observa-se maior conexão dos jovens com o âmbito local, quando se trata das políticas ambientais, conforme já foi ressaltado anteriormente. Entretanto, mais uma vez, não há registros de avaliações dos jovens acerca da atuação dessas autoridades, embora houvesse um campo no questionário para esse fim. Predominou o silêncio novamente, o que também é sintomático. Os jovens revelam que conhecem essas autoridades, principalmente os vereadores $(45,05 \%)$ e prefeitos $(23,19 \%)$, mas manifestaram pouco entusiasmo para avaliar a atuação desses agentes públicos. Tal postura pode ser explicada certamente pela baixa confiança dos segmentos juvenis nos órgãos e atores governamentais, conforme já foi apontado anteriormente pelos estudos de Gonzalez-Gaudiano e Maldonado-Gonzalez (2014) e Barros (2018c).

$\mathrm{Na}$ análise das poucas respostas abertas, o "conhecer" limita-se praticamente à visibilidade pela mídia local. Certamente, essa é a principal forma de contato entre representantes e representados na atualidade, mas como se trata principalmente dos vereadores e dos prefeitos, é relevante o fato de haver pouca interlocução entre esses agentes públicos e a juventude, o que indica a baixa interação mediante eventos, conferências, debates e demais formas de discussão política presencial, uma das alternativas consideradas pelas teorias democráticas como viáveis no âmbito local, a exemplo dos minipúblicos e das células democráticas (FUNG, 2004).

Quadro 3 - Você conhece autoridades eleitas que atuam ou já atuaram na defesa do meio ambiente?

\begin{tabular}{|c|c|c|}
\hline RESPOSTAS & $\mathrm{N}$ & $\%$ \\
\hline Vereador & 678 & 45,05 \\
\hline Prefeito & 349 & 23,19 \\
\hline Deputado estadual & 321 & 21,33 \\
\hline Governador & 124 & 8,24 \\
\hline Deputado federal & 23 & 1,53 \\
\hline Senador & 6 & 0,4 \\
\hline Presidente da República & 2 & 0,13 \\
\hline Não lembro & 2 & 0,13 \\
\hline Não conheço & 0 & - \\
\hline TOTAL & 1.505 & 100 \\
\hline
\end{tabular}

Fonte: Dados dos autores, 2018. 
Ao serem questionados sobre as contribuições dessas autoridades, os informantes destacam o papel que elas exercem na qualificação do debate ambiental (14,29\%), conforme exposto no Quadro 4. Praticamente com os mesmos percentuais, estão a apresentação de propostas para aperfeiçoar a legislação ambiental, a cobrança para melhorias na fiscalização, as denúncias em casos de omissão ou falta de atuação adequada dos órgãos ambientais e a apresentação de projetos de leis. As atribuições menos valorizadas pelos informantes são as campanhas de educação para a sustentabilidade, os possíveis alertas sobre riscos ambientais e os discursos. Isso mostra que os jovens valorizam mais aspectos pragmáticos do que discursivos quando se trata de políticas ecológicas, embora a qualificação do debate ambiental esteja em primeiro lugar.

A análise das repostas abertas mostra que, na visão deles, há uma diferença entre qualificar o debate ambiental e fazer discursos sobre temas ecológicos. No primeiro caso, estão comentários que associam essa qualificação diretamente com a formulação de propostas concretas, enquanto os discursos são associados a um modo de falar sem propósitos definidos e sem vínculo direto com um plano de ação. "Uma coisa é discutir para se tomar a melhor decisão e trazer benefícios para a cidade. Outra coisa é fazer discursos aleatórios, vazios de sentido e de aplicação”, relatou um dos informantes da pesquisa. Outro jovem também é enfático, ao afirmar que "eu não tenho o menor interesse por discussões extensas e vazias, sem um objetivo definido e sem um plano concreto de ação”. Por essa razão, os discursos de vereadores e prefeitos que se enquadram nessa perspectiva são criticados, por serem considerados "eleitoreiros”, ou seja, com a única finalidade de obter votos, como mostra um dos depoimentos:

O discurso ambiental eleitoreiro é repugnante, dá nojo e isso é muito comum durante as campanhas eleitorais, embora também ocorra durante todo o mandato de alguns políticos. É um discurso oportunista no pior sentido da palavra. A gente vê claramente que o cara não tem a menor afinidade com o tema, que nunca fez nada pela cidade em termos de ecologia, mas tem a cara de pau de se apresentar como defensor da natureza, quando se sabe que na prática defende os interesses de grandes produtores e devastadores. 
Quadro 4 - De que forma essas autoridades contribuem para o aperfeiçoamento das políticas ambientais?

\begin{tabular}{l|c|c}
\hline RESPOSTAS & $\mathrm{N}$ & $\%$ \\
\hline Ajudam a qualificar o debate ambiental & 237 & 14,29 \\
Apresentam propostas para aperfeiçoar a gestão ambiental & 232 & 13,98 \\
Atuam na cobrança para aperfeiçoar a fiscalização ambiental & 231 & 13,92 \\
Denunciam casos de omissão ou de falta de atuação adequada dos órgãos & 226 & 13,62 \\
ambientais & 217 & 13,08 \\
Apresentam projetos para aperfeiçoar as leis ambientais & 211 & 12,72 \\
Fazem discursos sobre temas ambientais & 162 & 9,76 \\
Alertam a sociedade e o cidadão sobre riscos ambientais & 121 & 7,29 \\
Promovem campanhas e ações de educação para a sustentabilidade & 22 & 1,33 \\
Outros & 1.659 & 100,00 \\
\hline
\end{tabular}

Fonte: Dados dos autores, 2018.

Em termos de políticas de sustentabilidade, a literatura sociológica atribui expressiva relevância ao papel do Estado, como indutor do desenvolvimento sustentável em áreas estratégicas. O foco é o desenvolvimento tecnológico e industrial, conduzido mediante novos modelos de planejamento, gestão e regulação, a cargo do Estado, ou seja, em consonância com o modelo de Estado assegurador (GIDDENS, 2010) e de ecossocioeconomia de Sachs (2007). É nesse sentido que os jovens reivindicam do Estado brasileiro, em primeiro lugar,medidas para reduzir o desmatamento das florestas (18,73\%), leis mais severas para coibir as práticas prejudiciais à sustentabilidade $(18,62 \%)$ e incentivos fiscais para empresas que adotem protocolos ecoeficientes na sua linha de produção $(16,78 \%)$, entre outras medidas.

Até mesmo a ambientalização das práticas burocráticas é lembrada pelos jovens por meio da adoção de licitações verdes nas compras públicas $(12,53 \%)$. Entre outras medidas relevantes na perspectiva dos jovens, estão incentivos fiscais para empreendimentos verdes na construção civil, na indústria automotiva e na fabricação de bens ecoeficientes $(10,86 \%)$, aumento dos investimentos para pesquisa e inovação tecnológica sustentáveis (10,40\%), incentivos fiscais para os consumidores que economizarem energia, água e gás $(8,27 \%)$ e oferta de transportes públicos eficientes para evitar o uso individual de automóveis (8,27\%). Em compensação, o apoio à criação de impostos verdes é baixíssimo (1,46\%), consoante com os dados do Quadro 5. 
Quanto aos discursos dos jovens, a ênfase está na falta de assertividade do Governo Federal para combater e reduzir os desmatamentos. Para a maioria dos informantes que se manifestaram no campo destinado à opinião, "é inaceitável que o Governo Federal não consiga conter a destruição das matas e florestas, a nossa maior riqueza natural”, conforme manifestou-se um dos depoentes. Outro alega que o Governo "é incompetente para fiscalizar e punir os responsáveis pela destruição do verde, contribuindo para estimular ainda mais a devastação, por causa da impunidade. Outro jovem declara que "é vergonhoso para o Brasil o que acontece diariamente na Amazônia, com o desmatamento para o plantio de pasto e a venda ilegal de madeira”. Em suma, os jovens atribuem ao Governo a responsabilidade pelo desmatamento, visto que a fiscalização é ineficiente: "Se o Governo não pune é porque não tem interesse de fato em combater o desmatamento”, sentenciou um dos informantes da pesquisa.

Quadro 5 - Quanto ao papel do Governo Federal, quais os aspectos que você considera mais eficientes para o setor ambiental?

\begin{tabular}{l|c|c}
\hline RESPOSTAS & $\mathrm{N}$ & $\%$ \\
\hline Adoção de medidas para reduzir o desmatamento das florestas & 978 & 18,73 \\
Adoção de leis mais severas para coibir as práticas prejudiciais à sustentabilidade & 972 & 18,62 \\
Incentivos fiscais para empresas que adotem protocolos ecoeficientes na sua & 876 & 16,78 \\
linha de produção & 654 & 12,53 \\
Adoção de licitações verdes nas compras públicas & 567 & 10,86 \\
Incentivos fiscais para empreendimentos verdes na construção civil, na indústria & 543 & 10,40 \\
automotiva e na fabricação de bens ecoeficientes & 8,27 \\
Aumento dos investimentos para pesquisa e inovação tecnológica sustentáveis & 542 & 2,36 \\
Incentivos fiscais para os consumidores que economizarem energia, água e gás & 432 \\
Oferta de transportes públicos eficientes para evitar o uso individual de & 123 & 7,46 \\
automóveis & 76 & 100 \\
Instituição de impostos para financiar projetos sustentáveis & 5221 & 2 \\
TOTAL
\end{tabular}

Fonte: Dados dos autores, 2018.

\section{Conclusões}

O foco do estudo foi analisar as percepções da juventude brasileira sobre as políticas ambientais, privilegiando a esfera governamental. A percepção dos respondentes é predominantemente pessimista, ao acreditarem que o Brasil está regredindo do ponto de vista de suas políticas para o setor ambiental. Essa percepção é influenciada por fatos recentes, como as alterações 
no Código Florestal em 2012, flexibilização dos critérios para a liberação de agrotóxicos e falta de medidas efetivas para a punição de grandes empresas de mineração em casos de rompimentos de barragens.

No caso específico da revisão do Código Florestal, as alterações são avaliadas de forma negativa pelos informantes, sob a justificativa de que "foi um grande retrocesso em termos ambientais, pois favoreceu o desmatamento para a plantação de espécies agrícolas pelos grandes produtores do ramo do agronegócio”. Outro dado que merece destaque é que a lei ambiental mais conhecida pelos jovens é o Novo Código Florestal, aprovado em 2012, embora seja também a mais criticada. As críticas e controvérsias certamente contribuíram para que a referida lei obtivesse maior visibilidade perante o público.

Quanto aos projetos em discussão, os informantes mostram maior conexão com a agenda ecológica local. Aqui é oportuno retomar os estudos citados na primeira parte do texto, que mostram essa afinidade dos segmentos juvenis com a esfera política local em seu sentido mais amplo, incluindo as políticas ambientais (BARROS, 2018c; MENEZES, 2015; JUNQUEIRA ET AL, 2015). Além da importância para a construção da identidade dos jovens, os espaços onde eles vivem e circulam geram vínculos de pertencimento, contribuindo para maior mobilização e engajamento em torno das questões que dizem respeito ao seu entorno imediato. Ademais, trata-se das gerações socializadas no contexto de intensos debates sobre a crise climática e apelos promovidos pelas mídias e pela escola em prol da conservação e proteção dos recursos naturais e o cuidado com o ambiente local (KRISCHKE, 2008; SCHARF; ROSA; CARVALHO, 2012; OLIVEIRA, 2012; CRISTO, 2017; SILVA, 2016).

É evidenciado o apreço dos jovens que participaram da pesquisa pelas ONGs ambientalistas no que se refere à atuação dessas entidades na defesa do meio ambiente. Essa preferência também foi registrada pela pesquisa de Gonzalez-Gaudiano; Maldonado-Gonzalez(2014). As instituições do Estado são pouco reconhecidas pelos respondentes. Até mesmo os três partidos políticos de orientação ecológica não gozam de visibilidade e reconhecimento dos jovens, um sinal de que esses partidos não conseguem estabelecer comunicação com a juventude. Esses dados reforçam e reiteram os estudos que mostram o distanciamento das juventudes da política representativa e dos partidos políticos (AUGUSTO, 2008; FLORENTINO, 2009; BARROS; MARTINS, 2016; BARROS, 2018c). 
Quanto às autoridades eleitas que atuam ou já atuaram na defesa do meio ambiente, os jovens reconhecem em especial os vereadores, prefeitos e deputados estaduais, o que demonstra a primazia das políticas locais na percepção da juventude. Mais uma vez, registra-se a relevância do contexto local para os jovens informantes da pesquisa. Mais do que o ato de proferir discursos, os jovens atribuem importância ao debate ambiental qualificado com vistas à proposição de mudanças ou de aperfeiçoamentos das políticas ambientais.

Em relação ao Governo Federal, os jovens o concebem como um ator indutor, regulador e assegurador da sustentabilidade ambiental, devido à sua relevância nas políticas ambientais. O foco da atenção dos jovens é o desenvolvimento tecnológico e industrial, modulado por novos modelos de planejamento, gestão e regulação, a cargo do Estado, ou seja, em consonância com o modelo de Estado assegurador (GIDDENS, 2010). Nesse sentido, os jovens reivindicam do Estado brasileiro, em primeiro lugar,medidas para reduzir o desmatamento das florestas, leis mais severas para coibir as práticas prejudiciais à sustentabilidade e incentivos fiscais para as empresas adotarem medidas ecoeficientes.

Do ponto de vista específico dos discursos dos jovens, a análise das respostas abertas nos mostra que se trata de perspectivas altamente críticas, especialmente em relação à ineficiência do Governo Federal no que diz respeito às políticas de combate ao desmatamento na Amazônia e aos desastres ambientais. Os jovens também são críticos em relação ao âmbito local, especialmente no caso dos políticos que adotam o que eles denominam de “discurso ambiental eleitoreiro", ou seja, manifestações em defesa da preservação ambiental apenas com a finalidade de conquistar votos do eleitorado.

Em linhas gerias, a pesquisa mostra que, sob a perspectiva das políticas em prol da sustentabilidade ambiental, os jovens são atores relevantes na transformação social. Apesar de ainda haver poucos estudos com esse enquadramento, os dados mostram como os eles são agentes desse novo processo civilizador, representado pela ambientalização das práticas, das relações sociais e dos discursos sociais, especialmente no caso da (re)formulação e execução das políticas ambientais.

Nessa ordem de ideias, seria positivo para o protagonismo juvenil nesse processo de ambientalização das práticas sociais a oferta pelo Estado de um leque maior de mecanismos para promover a inclusão dos jovens na (re) formulação das políticas ambientais. Apesar de haver estudos que ressaltam 
como a participação democrática de alguns segmentos juvenis foi positiva na área ambiental, a exemplo do Programa Nacional de Juventude e Meio Ambiente (SOUSA, 2017; BATISTA, BECKER e CASSOL 2015), ainda há muitos espaços para incrementar essa participação, a qual poderia ser beneficiada pela predisposição das juventudes para o engajamento em atividades e projetos da área ambiental.

\section{Referências}

AB’SÁBER, Aziz Nacib. (2010) Do código florestal para o código da biodiversidade. Biota Neotropica, v.10, n.4, p.331-335.

ACSELRAD, Henri. (2011) Discursos da sustentabilidade urbana. Revista Brasileira de Estudos Urbanos e Regionais, v.1, n.1, p.79-90.

ATTIAS-DONFUT, Claudine. (2015) Sociologie des générations: l'empreinte du temps. Paris: Fenix.

AUGUSTO, Maria Helena Oliva. (2005) Retomada de um legado: Marialice Foracchi e a sociologia da juventude. Tempo Social. v.17, n.2, p.11-33.

AUGUSTO, Nuno Miguel. (2008) A juventude e a (s) política (s): Desinstitucionalização e individualização. Revista Crítica de Ciências Sociais, n.81, p.155-177.

AUTIO, Minna; HEINONEN, Visa. (2004) To consume or not to consume? Young people's environmentalism in the affluent Finnish society. Young, v.12, n.2, p.137-153.

BAQUERO, Marcello; CREMONESE, Dejalma. (2009) Eleições municipais 2008: uma análise do comportamento eleitoral brasileiro. Editora da UNIJUÍ.

BARDIN, L. (2005) Análise de conteúdo. Lisboa: Edições 70.

BATISTA, Natália Lampert; BECKER, Elsbeth Léia Spode; CASSOL, Roberto. (2015) Um breve olhar sobre o Programa Nacional de Juventude e Meio Ambiente. GeoTextos, v.11, n.1, p.167-192.

BARGEL, Lucie; DARMON, Muriel.(2016) Socialisation politique. Paris: Centre Européen de Sociologie et de Science Politique.

BARROS, Antonio Teixeira. (2015) A Agenda Verde Internacional e seus Impactos no Brasil. Revista de Estudos e Pesquisas sobre as Américas, v.9, n.2, p.169-183. 
BARROS, Antonio Teixeira; MARTINS, Lúcio Meireles (2016) Impactos do Parlamento Jovem Brasileiro na motivação e participação política partidária dos egressos. Revista Debates, v.10, n.2, p.95-114.

BARROS, Antonio T; MARTINS, Lúcio M. (2017) Juventude e engajamento político despartidarizado: estudo sobre os egressos do Parlamento Jovem Brasileiro (2004-2013). Revista Latitudes, v.11, n.1, p. 205-254.

BARROS, Antonio Teixeira. (2015a) Política partidária e meio ambiente: a adesão dos partidos políticos brasileiros à agenda verde. Opinião Pública, v.21, n.3, p.693-733.

BARROS, Antonio Teixeira.Agenda Verde Internacional e seus Impactos no Brasil. (2015b) Revista de Estudos e Pesquisas Sobre as Américas, v.9, p. 160-191, 2015b.

BARROS, Antonio Teixeira. (2017a) The Internet as environmental media: strategies of Brazilian political parties. Ambiente \& Sociedade, v.20, n.1, p.183-202.

BARROS, Antonio Teixeira. (2017b) Brazil's Discourse on the Environment in the International Arena. Contexto Internacional, v.39, n.2, p. 421-442..

BARROS, Antonio Teixeira. (2018a) Ambientalistas acidentais: a adesão dos partidos políticos brasileiros ao liberalismo verde. Colombia Internacional, v.94, p.111-141.

BARROS, Antonio Teixeira. (2018b) A Esquerda Verde: Partidos Políticos e Ambientalismo Radical no Brasil. Dados, v. 61, n.2, p. 503-540.

BARROS, Antonio Teixeira (2018c). Juventude e poder político local: a percepção e o discurso de jovens sobre as eleições municipais de 2016. Sociedade e Estado, v.33, n.3, p.849-886.

BIERMANN, Frank. (2017) A World Environment Organization: solution or threat for effective international environmental governance? London: Routledge.

BOURDIEU, Pierre. (1983) A juventude é apenas uma palavra.

In: BOURDIEU, Pierre. Questões de sociologia. Rio de Janeiro: Marco Zero, p.112-121.

BRAND, Ulrich; WISSEN, Markus. Strategies of a Green Economy, contours of a Green Capitalism. 2015. In: VAN DER PIJL, Kees (Ed.). Handbook of the international political economy of production. Northampton: Edward Elgar Publishing.

BROWN, Lester R.; WOLF, Edward C. (1988) Reclaiming the future. New York: W.W. Norton..

BRUNET, Ignasi; PIZZI, Alejandro. (2013) La delimitación sociológica de la juventud. Última década, v. 21, n. 38, p.11-36. 
BURNS, Tom R. (2016) Sustainable development: Agents, systems and the environment. Current Sociology, v.64, n.6, p.875-906.

CARVALHO, I. C. M.(2012) Educação Ambiental: a formação do sujeito ecológico ( $6^{\mathrm{a}}$ ed.). 6. ed. São Paulo: Cortez

CASTRO, Lucia Rabello de. (2009) Juventude e socialização política: atualizando o debate. Psicologia: Teoria e Pesquisa, v.25, n.4, p. 479487.

CHAFFIN, Brian C. et al. (2016) Transformative environmental governance. Annual Review of Environment and Resources, v.41, n.123, p.399-423.

CHAKRABARTY, Dipesh. (2017) The politics of climate change is more than the politics of capitalism. Theory, Culture $\&$ Society, v. 34, n. 2-3, p. 25-37.

CHAMBOREDON, Jean-Claude. (2015) Jeunesse et classes sociales. Paris: Éditions Rue d'Ulm.

COFFEY, Julia; FARRUGIA, David. (2014) Unpacking the black box: The problem of agency in the sociology of youth. Journal of Youth Studies, v. 17, n. 4 , p. 461-474.

CORSTEN, Michael. (1999) The time of generations. Time $\mathcal{E}$ Society, v.8, n.2-3, p. 249-272.

CRISTO, Hélio Souza de. (2017) Juventude e meio ambiente: narrativa de jovens ambientalistas do estado da Bahia. Dissertação (mestrado). Universidade Estadual de Feira de Santana. Programa de Pós-Graduação em Educação.

DE LA TORRE, Héctor M. G. (2017) Sostenibilidad de la acción colectiva en el marco de las políticas, programas y proyectos de juventud. Caracterización de una experiencia en México (2004-2015). Ultima década, Santiago , v. 25, n. 47, p. 3-43.

DRYZEK, J. (1997) The Politics of the Earth: environmental discourses. New York: Oxford University Press.

DUNLAP, Riley E.; BRULLE, Robert J. (2015) Climate change and society: Sociological perspectives. Oxford University Press.

DUNLAP, Riley; MCCRIGHT, Aaron; Yarosh H. JERROD. (2016). The political divide on climate change: Partisan polarization widens in the U.S. Environment: Science and Policy for Sustainable Development, v.58, n.5: 4-23.

FEIXA, Carles; LECCARDI, Carmen. (2010) O conceito de geração nas teorias sobre juventude.Sociedade \& Estado, Brasília, Vl. 25 n. 2. 
FERNANDES, Jaqueline. (2010) Entre juventude e educação ambiental: relações e reciprocidades na caminhada dos jovens do Projeto Sombra da Mata. 2010. 142 f. Dissertação (Mestrado em Desenvolvimento Sustentável). Universidade de Brasília, Brasília.

FLORENTINO, Renata. (2009) Democracia Liberal: uma novidade já desbotada entre jovens.Opinião Pública, v.14, n.1, p. 205-235.

FUNG, Archon. (2004) Receitas para esferas públicas: oito desenhos institucionais e suas consequências. In: Coelho, V. S. P., Nobre, M. Participação e deliberação: Teoria democrática e experiências institucionais no Brasil contemporâneo. São Paulo: editora 34, p.173209.

FRANCHINI, Matías et al. (2017) The challenges of the anthropocene: from international environmental politics to global governance. Ambiente $\mathcal{F}$ Sociedade, v.20, n.3,p.177-202.

GAUTHIER, Madeleine. (2002) La jeunesse: un mot, mais combien de définitions. Définir la jeunesse, n.43,p.9-27.

GALLAND, Olivier. (2017) Sociologie de la jeunesse. Paris: Armand Colin.

GIDDENS, Anthony. (2019) The politics of climate change. Cambridge, Cambridge University Press.

GOHN, Maria da Glória. (2013) Os jovens e as praças dos indignados: territórios de cidadania. Revista Brasileira de Sociologia, v.1, n.2, p.205221.

GONDIM, Sônia Maria Guedes; FISCHER, Tânia. (2019) O discurso, a análise de discurso e a metodologia do discurso do sujeito coletivo na gestão intercultural. Cadernos Gestão Social, v. 2, n.1, p.9-26.

GONZALEZ-GAUDIANO, Edgar J.; MALDONADO-GONZALEZ, Ana Lucía. (2014) ¿Qué piensan, dicen y hacen los jóvenes universitarios sobre el cambio climático? Un estudio de representaciones sociales. Educar em Revista. Curitiba, n. spe3, p. 35-55.

HANNIGAN, John. (2014) Environmental sociology. London: Routledge.

HARDIN, Garrett. Extensions of the tragedy of the commons. (1998)

Science, v. 280, n.5364, p. 682-683.

INGLEHART, Ronald. (1977) La revolución silenciosa. Princeton: Princeton University Press.

IRAZÁBAL, Clara. (2017) City making and urban governance in the Americas: Curitiba and Portland. London: Routledge.

IRWIN, Alan. (2013) Sociology and the environment: a critical introduction to society, nature and knowledge. Cambridge: John Wiley \& Sons. 
JACOBBI, Pedro; GIATTI, Leandro Luiz. (2017) Nexos para a sustentabilidade: a busca por uma nova racionalidade. Ambiente $\mathcal{F}$ Sociedade, v.20, n.2, p.12-24.

JUNQUEIRA, Alice; SCARPELINI, João Felipe; MONTIEL,Talita. LA SALA, Safira de; QUENTAL, Cesar Augusto; CUNHA, Diego da; TANAKA, Emi et al. (2015) Juventude e Território: Um olhar jovem sobre governança da cidade. United Nations Human Settlements Programme (UN-HABITAT).

KRISCHKE, Paulo J. (2008) Ecologia, juventude e cultura política. Estudos em Jornalismo e Mídia, v.3, n. 2, p. 161-167.

LAGREE, Jean Claude. (1992) De la sociologie de la jeunesse à la sociologie des générations. Les Sciences de l'éducation pour l'ère nouvelle, v.3, n.4, p. 19-27.

LEFÈVRE, Fernando; LEFEVRE, Ana Maria Cavalcanti; Teixeira, Jorge Juarez Vieira. (2000) O Discurso do Sujeito Coletivo. Uma nova abordagem metodológica em pesquisa qualitativa. Caxias do Sul: EdUCS.

LEFF, Henrique. (2015) Political ecology: a Latin American perspective. Revista Desenvolvimento e Meio Ambiente, n.35, p.29-64.

LEFF, Henrique. (2017) Power-knowledge relations in the field of political ecology. Ambiente \& Sociedade, v.20, n.3, p.225-256.

LIM, Michelle; SØGAARD JØRGENSEN, Peter; WYBORN, Carina. (2018)

Reframing the sustainable development goals to achieve sustainable development in the Anthropocene-A systems approach. Ecology and Society, v. 23, n.3, sem paginação.

LINSTONE, H. A.; TUROFF, M. (1975) The Delphi method: techniques and applications. Massachusetts: Addison-Wesley.

LÜCHMANN, Lígia Helena Hahn. (2007) A representação no interior das experiências de participação. Lua Nova, n. 70, p.139-170.

LOZANO VICENTE, (2014) Agustín. Teoría de teorías sobre la adolescencia. Última década, v. 22, n. 40, p.11-36.

LUKE, Timothy W. (2015) The climate change imaginary. Current Sociology, v.63, n.2, p.280-296.

MAIA, Gretha Leite. (2013) A juventude e os coletivos: como se articulam novas formas de expressão política. Revista Eletrônica do Curso de Direito da UFSM, v. 8, no. 1, p.58-73.

MANNHEIM, Karl. (1968) O problema da juventude na sociedade moderna. In: Sociologia da Juventude, I. Rio de Janeiro: Zahar Editores.

MARQUES, Joana Brás Varanda; FREITAS, Denise de. (2018) Método DELPHI. Pro-Posições, v. 29, n.2, p. 389-415. 
MCNEILL, John Robert. (2001) Something new under the sun: An environmental history of the twentieth-century world (the global century series). Norton \& Company: New York / London.

MENEZES, Elisangela Ferreira. (2015) A representação do lugar: um estudo sobre juventude ribeirinha da comunidade de Nazaré-RO. 2015. 135 f. Dissertação (Mestrado) - Programa de Pós-Graduação em Geografia, Fundação Universidade Federal de Rondônia, Porto Velho.

MÜLLER, Elaine. (2009) Repensando a problemática da transição à adultez: contribuições para uma antropologia das idades. Política \& Trabalho, v. 31, p.107-125.

OLIVEIRA, Sidney Santos. (2018) Juventudes e política: uma análise das formas e modalidades de participação dos jovens universitários da Grande Recife. Revista Cadernos de Ciências Sociais da UFRPE, v.1, no. 12: 60-82.

ORLANDI, Eni. (1997) As formas do silêncio no movimento dos sentidos.São Paulo: Cortez.

PEPERMANS, Yves and Maeseele, Pieter. (2016) The politicization of climate change: problem or solution? Wires Climate Change, v.7, n.4, p.478-485.

PERSSON, Johannes et al. (2018) Toward an alternative dialogue between the social and natural sciences. Ecology and Society, v.23, n.4, p.14-31.

PITELIS, Christos N. (2013) Towards a more 'ethically correct' governance for economic sustainability. Journal of Business Ethics, v.118, n.3, p.655-665.

REGUILLO, Rossana. (2003) Ciudadanías juveniles en América latina. Última década, v.11, n.19, p.11-30.

REVILLA CASTRO, Juan Carlos. (2001) La construcción discursiva de la juventud. Papers: revista de sociologia, n.63/64, p. 103-122.

ROHRSCHNEIDER, Robert and Miles, Matthew. (2015) Representation through parties? Environmental attitudes and party stances in Europe in 2013. Environmental Politics, v.24, n.4, p.617-640.

ROBERTS, Ken; PARSELL, Glennys. (1992) The Stratification of Youth Training. British Journal of Education and Work, v. 5, n.1, p. 65-83.

RYAN, Daniel. (2017) Politics and climate change: exploring the relationship between political parties and climate issues in Latin America. Ambiente \& Sociedade, v.20, n.3, p.271-286.

SACHS, Ignacy. (2007) Rumo à ecossocioeconomia: teoria e prática do desenvolvimento. Cortez.

SCHARF, Edson Roberto; ROSA, Célio Paulo; Denise OLIVEIRA. (2012)

Os hábitos de consumo das gerações y e z: a dimensão ambiental nos contextos familiar e escolar. Contextus, v. 10, n.11, p.48-60. 
SANTILLI, Juliana. (2005) Socioambientalismo e novos direitos: proteção jurídica à diversidade biológica e cultural. São Paulo: Editora Peirópolis LTDA.

SILVA, Tarcísio Augusto Alves. (2016) Políticas públicas de juventude e meio ambiente: o que a percepção socioambiental dos jovens pode dizer? Ciências Sociais Unisinos, v. 52, n.2,p.214, 222.

SILVA, José Irivaldo Alves Oliveira. (2016) Reflexões teóricas acerca da "crise ambiental": possibilidades de novas orientações para as políticas públicas ambientais. Ciências Sociais Unisinos, v. 52, n. 2, p.205-213

SMITH, Richard et al. (2016) Green capitalism: the god that failed. London: College Publications.

TEIXEIRA COELHO, José. (1997) Cultura e cultura política dos jovens. Revista USP, n. 32, p. 156-165.

VAN DE VELDE, Cécile. (2015) Sociologie des âges de la vie. Paris: Armand Colin.

VOGLER, John. (2012) Global commons revisited. Global Policy, v. 3, no. 1, p. 61-71.

YEARLEY, Steven. (2014) The Green Case (Routledge Revivals): A Sociology of Environmental Issues, Arguments and Politics. London: Routledge.

WALLACE, Claire; CROSS, Malcolm. (2018) Youth in transition: the sociology of youth and youth policy. London: Routledge.

WANNER, Thomas. (2015) The new 'passive revolution'of the green economy and growth discourse: maintaining the 'sustainable development'of neoliberal capitalism. New Political Economy, v.20, n.1, p.21-41.

\section{(cc)) BY}

Licenciado sob uma Licença Creative Commons Attribution 3.0 